Commentary on Psychotherapy as a Human Science: Clinical Case Studies Exploring the Abyss of Madness

\title{
Empathy and Otherness: Humanistic and Phenomenological Approaches to Psychotherapy of Severe Mental Illness
}

\author{
ELIZABETH PIENKOS ${ }^{\mathrm{a}, \mathrm{b}}$ \& LOUIS A. SASS ${ }^{\mathrm{a}}$
}

\author{
a Graduate School of Applied and Professional Psychology, Rutgers University \\ $\mathrm{b}$ Correspondence concerning this article should be addressed to Elizabeth Pienkos, GSAPP—Rutgers University, \\ 152 Frelinghuysen Road, Piscataway, NJ 08854. \\ Email:epienkos@gmail.com
}

\begin{abstract}
In this commentary, we respond to Atwood's (2012) article, "Psychotherapy as a Human Science: Clinical Case Studies Exploring the Abyss of Madness," by highlighting some of the theoretical ideals that guide Atwood's writing and his therapy work. In particular, we consider how these case studies fit into the larger paradigm of humanistic psychology, and how this perspective informed Atwood's work with his clients, providing him with the understanding and empathy that facilitated the therapeutic healing he describes. We also consider the different, but complementary, idea in phenomenological psychiatry of "radical otherness," which suggests the fundamental impossibility of complete empathy, and how this can be therapeutic, particularly when treating cases of schizophrenia. Finally, we discuss the contributions of phenomenology to the understanding of schizophrenia, and its implications for treatment.
\end{abstract}

Key words: humanism; schizophrenia; phenomenology; empathy; radical otherness; case studies; clinical case studies

George Atwood's "Psychotherapy as a Human Science: Clinical Case Studies Exploring the Abyss of Madness" (2012) employs several case studies of patients with severe mental illness to illustrate a method of therapy that he characterizes as "phenomenologically, humanistically, existentially, and psychodynamically informed” (p. 1). Such an article is a refreshing addition to the corpus of clinical case studies. As a third-year graduate student in clinical psychology and a professor whose research interests have focused on schizophrenia, we come to this article with different backgrounds, but both of us found much to be inspired by in Atwood's article. The humanistic perspective, which is perhaps best summarized by the assertion "We are all more simply human than otherwise," is often implicit in the training of young psychologists today, but is not typically expressed as clearly and as vibrantly as we see in Atwood's approach to treatment. Works like this are essential in reminding clinicians that we are not merely treating symptoms, but engaging with fellow human beings. This can be 
especially easy to forget when treating severely mentally ill patients in fast-paced, managed care settings.

In what follows, we will attempt to highlight some of the theoretical ideals that guide Atwood's writing and his therapy work. We will also explore how Atwood's work, and the larger field of humanistic psychology, may inform and be informed by other approaches to psychopathology. In so doing, we will focus particularly on phenomenology, with which humanistic psychology obviously overlaps and shares some common values, but which we feel can also offer a form of "radical empathy" that can perhaps augment Atwood's already empathic approach. Although we are largely in agreement with Atwood's position, in this response we will also consider some possible areas of disagreement or, at least, differing emphasis.

\section{HUMANISTIC PSYCHOLOGY}

As is well known, humanistic psychology developed in the late 1950s as a response to two major trends in psychology at that time, behaviorism and Freudian psychoanalysis. The founders of this movement, including Gordon Allport, Abraham Maslow, and Carl Rogers, felt that contemporary psychology did not focus enough on values, morality, or other aspects of what it means to be human (Moss, 2001). A number of theories grew out of this new paradigm, including Maslow's theory of human needs and self-actualization; Rogers’ person-centered therapy, which emphasized unconditional positive regard and empathic understanding; and Rollo May's existential psychotherapy, which focused on the more tragic elements of human existence. What united these approaches to psychology was their emphasis on the particular struggles in being human and on humankind's innate dignity and worth.

The influence of humanism is clearly present in Atwood's case vignettes and the description of his interventions. For example, he suggests that when working with Anna, the patient who experienced Atwood's failures in understanding as "death rays...flowing out of my eyes," the success of the treatment seemed to rest on his affirmation of Anna's worth as a person. In contrast to her mother, who treated Anna as a sick patient, a psychiatric object in need of treatment, Atwood's work in interpreting and understanding Anna's dreams and delusions conveyed to her that her experience was meaningful. Her psychosis was not merely a conglomeration of psychiatric symptoms, but the expression of feelings worthy of understanding. It was this understanding, and the compassion associated with it, that allowed Anna to feel like a human among other humans, eventually permitting her to leave her psychotic symptoms behind. Similarly, when Atwood ascribes meaning to another patient's auditory hallucinations, he seems to give her permission to understand herself, to have compassion for herself as a person who is not crazy, but who is experiencing significant stress and confusion due to the nature of her husband's attacks on her character. All this is admirable, and very eloquently described in Atwood's vivid clinical accounts.

The fundamental tenets of humanism are applied even to Atwood's work with Grace, the patient with grandiose delusions of religious content. Grace challenges Atwood's boundaries and limits as a therapist on numerous occasions, e.g., when she disrupted his game of pool with another patient, cutting him off when she disagreed with his interpretations, and commanding him to listen to her and to obey her wishes. When she demands that Atwood call her old 
counselor, with whom she has had no contact for numerous years, to arrange a meeting between the two of them, Atwood, under the guidance of his supervisor, strongly refuses and firmly states that their relationship, Atwood's and Grace's, is the only important one in the present moment.

In making this statement, Atwood is acting on his belief that the underlying humanity in his patient can tolerate this rejection of her demand. Rather than pitying her in her psychotic state and thus either acquiescing to or ignoring her demands, Atwood speaks to her as one person-with-dignity to another, pushing her to enter the intersubjective world of reason and meaning where he and most others reside. Probably largely due to the strength of their relationship and the trust that Atwood had cultivated with Grace over their many hours together, Grace responds positively to this challenge, and allows herself to be transformed by it.

The values of emphasizing the strength of the relationship, the real difficulties of the patient, and the innate ability of the patient to "get better" are not restricted, of course, only to humanistic forms of psychotherapy. They can also be seen, for instance, in Dialectical Behavior Therapy (DBT), a therapy with roots in cognitive behavioral therapy that was designed for patients with Borderline Personality Disorder. (Incidentally, one might argue that Grace has some Borderline qualities as well.) Indeed, the core notions in DBT of acceptance and mindfulness draw significantly on the spiritual experience of its founder, Marsha Linehan (Carey, 2011), suggesting that this therapy is compatible with the values of humanistic therapy advocated by Atwood. Reflecting these values, Linehan has stated that "The tendency of many therapists to tell...patients to try harder, or imply that they indeed are not trying hard enough, can be one of the patient's most invalidating experiences in psychotherapy" (1993, p. 106); instead, she insists that therapists assume that their patients are already trying their hardest. We would suggest that the belief that the patient simply does not have the capacity to improve can be equally invalidating in the treatment of patients with psychotic disorders. Atwood elegantly avoids this pitfall by speaking directly and respectfully to Grace.

Atwood emphasizes the fact that treatment failures, as when patients prematurely terminate therapy or do not seem to get better, can frequently result from failures in empathy. Atwood describes two such cases: Thomas, who experiences delusions of being able to control his therapist's mind, and who leaves treatment when the therapist insists that these delusions basically result from a primary-process substitution of fantasy for reality; and Mary, who, prior to beginning therapy with Atwood, received hospitalization, medication, and ECT in an attempt to suppress and control her psychotic symptoms.

Atwood's analysis of these two cases suggests that he sees the problem here as lying in the distinction that psychiatry is too eager to make between right and wrong, real and imaginary, normal and psychotic. It appears that Mary's delusions and hallucinations-as commonly occurs with patients with severe mental illness-were only seen as manifestations of something "wrong," as the result of a disease entity that could be controlled with the standard (though extreme) tools of psychiatry. In Thomas' case, his therapist was able to see that the delusions might be meaningful, but his interpretations relied on a classically Freudian formulation of "true" reality compared to psychotic fantasy. In order for Thomas to get better, according to this analyst, Thomas had to be made to understand the difference between the two, to see that his symptoms were merely the manifestations of intrapsychic conflict, and that they had no 
relationship to the objective world. In so doing, Atwood suggests, this therapist failed to appreciate the meaning of these symptoms and the way in which they reflected the patient's legitimate recognition of a dimension of reality in his experience.

Some authors have discussed the tendency of Cognitive Behavioral Therapy for Psychosis (CBTp) to make this same mistake. One of the major techniques in this therapy is to teach patients to question their own delusions by evaluating them against objective facts in the world. Research on the efficacy of this therapy has provided mixed results. There is evidence of a significant decrease in symptoms in follow-up interviews (e.g., Wykes et al., 2008), though a meta-analysis of CBTp studies calls the effectiveness of this treatment into question (Lynch et al., 2010). But such an approach, whether couched in the language of psychoanalysis or of CBT, fails to acknowledge the here-and-now meaning for the patient of their delusions and hallucinations - a meaning that, Atwood strives to show, may be as valid and real for the patient as any kind of “objective reality," and as a result cannot be disputed with common reality-testing techniques. Delusional beliefs may express the truth about someone's experience, such as a profound feeling of loneliness, the experience of being misunderstood and objectified, or of a dawning sense of one's relevance for another, in a way that, for whatever reason, words or other communications may fail at conveying. Attempts to argue that such beliefs are "false" fail to acknowledge the existential reality of the experiences that underlie them and can be felt as invalidating by patients, as Atwood suggests is the case with Thomas.

It is worth noting, however, that for some patients, some of the time, hearing that their symptoms are not based in reality can be therapeutic. Elyn Saks, a specialist in mental health law and the author of the memoir The Center Cannot Hold about her personal experience with schizophrenia, has emphasized the importance of her therapist's disputing of the reality of her delusions. During periods of psychosis, she writes, "I desperately want to hear that my scary thoughts are my illness acting up, and not that they should be entertained and believed,” (Saks, 2011, p. 63). It is dangerous to overgeneralize, however. Another schizophrenic patient observed that her therapist's appeals to reality were often ineffective and seemed somehow to miss the point: "Dr. Rosen will try to convince me, through Socratic reasoning, that the appointment is actually happening... But the thing is, it goes nowhere. She can reason with me like that, and it doesn't in any way change my mind. I'm perfectly aware that I can navigate space and move in time, and at the same time, none of it feels like it's happening. It just doesn't make a difference," (Aviv, 2010, p. 46).

Recent work on delusions (Parnas, 2004; Parnas \& Sass, 2001; Sass \& Pienkos, in press) has suggested that some schizophrenic delusions are, in fact, quite different from everyday beliefs and assessments about the intersubjective world, and as such, might not be appropriate targets for the kinds of appeals to rationality and reality-testing that are employed in the thoughtchallenging of cognitive therapy. Neither this research nor statements from patients such as those presented above provide definite guidelines about how to respond to and work with psychotic delusions in the therapeutic setting. They do suggest, however, that Atwood's empathic and humanizing approach, with its emphasis on respect for the reality of the patient's experience, may well be crucial to further work with such patients. 


\section{UNDERSTANDING AND THE ROLE OF PSYCHODYNAMIC PSYCHOTHERAPY}

Atwood appears to lean on some principles of psychodynamic psychotherapy in order to decipher the anomalous experiences of his patients. In particular, Atwood explores the past in order to uncover unresolved conflicts which he uses to interpret his patients' delusions and interpretations. In this way, for instance, Grace's belief in her sexual union with Jesus Christ can be understood as a manifestation of her desperate attempts to cope with the trauma of her father's suicide, the confusion of her emerging sexuality, and her need to find meaning and comfort. In their book Psychotherapy of Schizophrenia (1977), Karon and Vandenbos discuss the importance of psychoanalytic psychotherapy in working with schizophrenic patients, suggesting that

the distortions of schizophrenic individuals are attempts to deal with their problems symbolically. The essence of the symbol is that the contents of the unconscious are expressed, and yet the individual is preserved from the awareness of what he is expressing (p. 145).

On this view it is the role of the therapist to decipher the problems that have been hidden in the psychotic symptoms, and to help the patient gradually confront and deal with these problems.

Atwood contrasts this model of understanding with the medical model of mental illness, which "pigeonholes clients into discrete mental disorders," rather than treating the "complex life issues" that Atwood sees as the root of many psychotic disorders (p. 13). In describing one patient, he states, "The auditory hallucinations and the associated paranoia were thus not 'symptoms of an illness,' they were expressions of my patient's efforts to psychologically survive," (p. 16); and he suggests that "the phenomena of 'psychosis' [are] relative to a certain situational context," and that they are not merely manifestations of "a pathological process occurring somehow inside the patient” (p. 9). Atwood calls for a return to phenomenology, to a focus on the lived experiences of individual patients as human beings, not as mere deviations from some standard of normalcy. We certainly agree with this latter view, and believe that it can provide a necessary counterpoint to the dominant, often overly simplistic medical model of mental illness.

\section{PHENOMENOLOGY AND OTHERNESS}

There are, however, also some dangers inherent in the humanistic project and the critique of "pathologizing" tendencies. A number of those who have been involved in the recent revival of phenomenological psychiatry (continuing the intellectual tradition of Karl Jaspers, Eugene Minkowski, Wolfgang Blankenburg, and others) have suggested that, however "much more simply human" patients with severe mental disorders are than was once believed, there can still be an "otherwise" that is essential to understanding these disorders, especially schizophrenia. It is worth recalling that Jaspers, who arguably founded the movement of phenomenological psychiatry with his encyclopedic text General Psychopathology (1963), differentiates schizophrenia from other psychopathology by stating that, while affective or other disorders can be understood as “an exaggeration or diminution of known phenomena,” in schizophrenia the 
transformation of experience is so extreme as to render it "ununderstandable, 'mad' in the literal sense,” (p. 577). On this view, there is something profoundly different about schizophrenia that prevents our empathizing with these experiences as comparable to normal mental processes.

There are, however, forms of phenomenological understanding that place less emphasis on the sheer fact of empathic attunement. In a classic article Henri Ellenberger (1958) has described how psychiatric phenomenology can serve to explain subjective states of mind in three ways: 1 , Descriptive phenomenology, which relies on patients' descriptions of their own subjective experiences; 2, Genetic-structural phenomenology, which attempts to find a common core or "genetic factor" in psychopathology that can render intelligible the various symptoms; and 3, Categorical analysis, which strives to reconstruct the patient's experience by considering the distortions of such fundamental aspects of reality as time, space, causality, and materiality. Both classical and contemporary writers in the phenomenological tradition have used these methods to attempt to understand schizophrenia, in a way, from within the experience. The application of these methods can lead to forms of phenomenological understanding that differ somewhat from Atwood's approach, with its emphasis on empathic understanding of schizophrenia as a manifestation of what appear to be essentially normal (albeit exaggerated) experiences of human problems and conflicts. Ratcliffe (in preparation) has explicitly suggested that an empathic understanding of others can involve "an engagement with others' experiences which suspends the usual assumption that both parties share the same modal space” (p. 13), recognizing that the other person may well experience him or herself, or the world, in a way that lies well outside our own implicit assumptions of experience. He calls the recognition of profound difference between oneself and another "radical empathy," and suggests (and we would agree) that the tools of phenomenology are uniquely suited to exploring these differences.

Related concerns are suggested by the phenomenological philosopher Levinas (1969), who has emphasized what might be understood as the absolute otherness of the Other. Levinas states that in any encounter with another human being, there will always be an element of the Other that is beyond comprehension. On his view it would be problematic to be too quick to assume the possibility of a complete or near-complete empathic understanding of the other person, for this is liable to diminish and objectify the other person's sovereignty as an independent being. The truly empathic therapist will always recognize that, no matter how sensitive his conceptualization of a patient, there will always, indeed must always, be a part that resists understanding. The latter point is hardly controversial, and we have no doubt that Atwood would agree with this point.

We would suggest, however, that this point is especially important to remember when considering the profound disturbances that can occur in schizophrenia (which we will describe below), and that Atwood's "humanistic" approach may not always pay sufficient attention to this difference. Specifically, we disagree that in the majority of cases of severe psychopathology, therapeutic success is dependent on providing "a little human understanding” (p. 18). Although Atwood is clear about the fact that his patients" "difficulties and vulnerabilities continued" (p. 19) long after the interventions described in his paper, we feel that it is important to discuss other aspects of severe mental illness in order to have a more completely informed understanding of what treatment of such disorders entails and can hope to accomplish. 
It is true that Jaspers may well have exaggerated the incomprehensibility of schizophrenia (our own work on schizophrenic disputes Jaspers' view). Still, what has been called Jaspers' "doctrine of the abyss" did derive from some valid intuitions about the strangeness of schizophrenia as a mode of being. Schizophrenia does involve experiences that are quite radically outside the norm, and failure to recognize this is likely to miss something important about schizophrenic experience. Such an error would, in our view, be a particularly extreme version of the point to which Levinas calls our attention: namely, that there is always something beyond our understanding of others, and that a failure to appreciate this dimension of incomprehensibility or mystery is to miss something of the other's humanity.

\section{PHENOMENOLOGICAL THEORIES OF SCHIZOPHRENIA}

Phenomenologists have recently hypothesized that the fundamental feature in schizophrenia is best conceived as a disturbance of minimal self-experience, or ipseity. (Although phenomenologists have certainly explored the experience of depression, and to a lesser extent, bipolar disorder, in what follows, we focus on schizophrenia as an example of how phenomenology might contribute to humanistic methods.) Ipseity refers to a foundational aspect of what it means to be human, namely, the implicit sense that this experience is my experience, that it is happening to me. This basic level of self is the foundation for more explicit aspects of consciousness, such as thinking about what $I$ want, acting in accordance with my values, or developing a sense of social identity. The disturbed-ipseity model is comprised of two interrelated aspects, including diminished self-affection, which describes "the implicit sense of existing as a vital and self-possessed subject of awareness,” and hyperreflexivity, which describes "forms of exaggerated self-consciousness in which aspects of oneself are experienced as akin to external objects” (Sass \& Parnas, 2003, p. 427).

This disturbance of the self is hypothesized to generate a number of interrelated symptoms, which have been systematized in a semi-structured interview format titled the Examination of Anomalous Self-Experience (EASE; Parnas et al., 2005). The types of experiences described within include changes in the experience of cognitive processes, in the basic sense of the self, in the experience of the body, in the felt differentiation between self and other, and in one's values and beliefs about the world. Other phenomenological alterations associated with schizophrenia may pertain more to one's experience of the external world, e.g., of objects, space, or other persons, some of which are included in the Bonn Scale for the Assessment of Basic Symptoms (Gross et al., 2008) and which will be the subject of an interview format that we are in process of constructing (the EAWE: Examination of Anomalous World Experience).

In considering how this model relates to the humanistic and psychodynamic conceptualization of psychosis offered by Atwood, we would suggest that a psychotic episode may indeed be triggered by intolerable levels of stress or conflict, and may well result in symptoms that have content related to the patient's personal history. However, the very form of the psychosis, and the types of symptoms that appear, may be related to a more fundamental disturbance of selfhood, something that seems unlikely to be explicable on the basis of inter- or intrapsychic conflict, but that signifies a disruption of many of the most basic ways we experience ourselves and the world. 
Evidence that phenomenological investigations can indeed convey empathy and understanding, precisely by recognizing what is otherwise in persons with psychosis may be seen in interviews that have been done with the EASE (Parnas et al., 2005). Many of those who have performed or observed such interviews (including ourselves) have seen that patients can feel quite moved in being asked about these experiences. Indeed, many have stated that no one has ever asked them about such things before, and that it is a relief to know that such experiences are not unique to them but have actually been described by others before them. One patient was able to recognize himself quite clearly in the disturbed-ipseity model, stating, "This does describe what's been going on...I haven't given it a name before. . . It's amazing how much this (the selfdisturbance model) relates to what's been going on for me,” (Nelson \& Sass, 2009, p. 496). His therapist noted that the patient was "more enlivened than ever" when relating this model to his own experience; in this case, the fact that the therapist seemed to be familiar with significant aspects of the patient's experience, even though he himself had not experienced them, seemed to strengthen the therapeutic relationship and to enable the patient better to understand the nature of his psychotic vulnerability. Some authors have even suggested that that there is a sense in which the praecox feeling (the sense of encountering something alien when interacting with a person with schizophrenia) can itself be a form of empathy, at least in the sense that it implies a recognition of the profound nature of the change that have occurred for the patient (Ratcliffe, in preparation; Lysaker et al., 2005; Sass, 1992).

In a 2009 article by Nelson and Sass, the authors describe the treatment of a patient with schizophrenia that is informed by the phenomenological model of disturbed ipseity. The authors describe this approach to therapy as employing

(a) strategies that provide an intersubjective space where patients can evolve a more robust pre-reflective self-awareness (first-person perspective), second-person perspective, and experience of trustworthy relationships when encountering others; (b) empathic attunement afforded by the phenomenological approach's sensitivity to psychotic experience; and (c) strategies that encourage a form of immersion or absorption in present activity, including mindfulness and creative "flow." (p. 492)

Nelson and Sass further discuss how therapies that emphasize self-reflection and intensive focus on cognitions (such as forms of CBT) can at times be harmful for patients, for they may risk exacerbating the hyperreflexive element in ipseity disturbance. Some of these recommendations would certainly be congruent with Atwood's depiction of humanistic psychotherapy (e.g., the emphasis on establishing trustworthy relationships and on attunement). However, the phenomenological sensitivity to the strangeness or otherness of schizophrenic experience can also inform the treatment, so that it may address the particular needs and vulnerabilities that are unique to schizophrenia (i.e. the need for developing a first-person perspective, the emphasis on absorption in an activity, and the wariness toward techniques that encourage too much self-reflection).

Phenomenological theory may also assist a therapist in forming hypotheses about the form of various symptoms, which can complement a psychodynamic understanding of the content of the symptoms. In the case described by Nelson and Sass, for example, the patient complained of, among other things, “'out of body’ experiences, which involved watching 
himself from another part of the room” (p. 492) and “of feeling the sense of a 'buffer' between himself and the rest of the world, as though he could not engage or contact the world and others directly” (p. 493). The disturbed ipseity model sees these symptoms as evidence of disturbed presence, a feeling of alienation from one's own experience. These symptoms were manifestations of the patient's psychotic vulnerability, his latent ipseity disturbance that could be triggered in times of stress.

One of the particular stressors for this patient was his relationship with a girlfriend who was particularly controlling and intrusive. The therapist hypothesized that the girlfriend's persistent monitoring of the patient's behavior triggered "an inner vigilance and anxious monitoring of the self by the self" (p. 494) and a defensive reaction of removing himself psychically from what he perceived as interpersonally threatening. This resulted in the patient's feeling that he existed somehow outside himself and that he was unable to engage naturally in the world. The therapeutic work involved shaping the patient's relationship to his girlfriend so that it would be less controlling, as well as desensitizing him to close relationships with others so that they would not seem as threatening.

The disturbed ipseity model also provides awareness of the potential for too much empathy, which the schizophrenic patient may experience as intrusive and threatening. Lysaker et al. (2005) have noted that "interpersonal relationships can be so threatening that some persons with schizophrenia will actively disrupt meaningful relations in the interest of maintaining at least a minimal sense of self" (p. 337). In our view, conveying a sense of having "too much empathy” can actually be a danger in all types of therapy, with all types of patients. It is, however, particularly dangerous for schizophrenics - both for those patients who may be skeptical of the therapist who claims to understand too much (schizophrenic patients are often acutely aware of the difference of their subjective life in comparison to those around them), and also for those patients who may feel uniquely at risk of losing their independence or identity if they are too well understood.

R.D. Laing (1960) called this latter type of experience “engulfment.” He describes how a person with a fragile sense of identity "dreads relatedness as such, with anyone or anything...because his uncertainty about the stability of his autonomy lays him open to the dread lest in any relationship he will lose his autonomy and identity" (p. 44). One schizophrenic patient described it as follows: "I'm getting to be more humane. Will it ruin my brain? All this humanity is upsetting my own special framework. It's polluting me” (Stanghellini \& Ballerini, 2007, p. 138). Particularly in relation to the therapeutic situation, Lysaker et al. (2005) have noted that many schizophrenia patients appear to experience "a terrifying sense of losing ownership over one's own life story if it should be understood by the therapist” (p. 337). Such dangers are quite possible, we suggest, in the type of humanistic and psychodynamic psychotherapy that is described in Atwood's paper, which emphasizes the human and understandable side of its patients. We must also acknowledge, however, that proponents of phenomenologically-informed therapies can run a similar risk if, in proposing to detail the very differences that characterize schizophrenia, they too pretend to understand too much, thereby neglecting to recognize or respect the "otherness" of the Other. 


\section{CONCLUSION: SAMENESS AND OTHERNESS}

In concluding we wish to acknowledge as well that putting too excessive a focus on the "otherness" of this disorder might impede one's ability to provide therapy for such individuals. If I experience someone as so completely different, as inhabiting a space of possibilities that does not intersect with my own, it may be difficult, if not impossible to imagine meaningful communication. My attention may become solely focused on the "otherness" of the individual and lose sight of the ways in which he is "much more simply human.” Elyn Saks (2011) notes that in psychotherapy, there is almost always a nonpsychotic part of the patient that can, and should, be appealed to: "One can speak to that part. One can help the person see the meaning of what they are thinking and feeling, and that can help interrupt the symptoms," (p. 63). Atwood's clinical examples certainly show us the profound effects that can result from appealing to the nonpsychotic part in a deeply respectful and humanizing way.

Regardless of one's clinical orientation, it seems important to help a psychotic patient make sense of experiences that can be confusing and terrifying. At times this may involve conveying a willingness to listen to and accept the strangeness of these experiences. It may also involve understanding schizophrenic symptoms as related to a core disturbance of the self in order to apply therapies targeted at restoring or coping with the sequelae of this fundamental disruption. At other times, therapy may involve exploring how some of these symptoms may be meaningful expressions of deeply buried conflicts, while conveying one's experience of the patient as a valuable and understandable human being.

Knowing when to emphasize the "otherness" and when to emphasize the "humanness" of a patient may rely, to a large extent, on the clinical judgment of a practitioner and her understanding of a patient's experience in each moment. However, we believe that an awareness of both these elements, especially when treating more severely disturbed patients, is essential for a full experience and expression of empathy. We further believe that phenomenology and humanism are complementary approaches toward achieving this goal. Sadly, both of these perspectives, and their implications for treatment, are often underemphasized in the training of new mental health practitioners. This is one reason why it is so important for experts like George Atwood to remind us of their continued importance today. Atwood's vivid article offers a particularly eloquent argument for the value of engaging with the subjective life of our patients, even —or perhaps especially —in those cases that challenge our natural inclinations toward empathy.

\section{REFERENCES}

Atwood, G.E. (2012). Psychotherapy as a human science: Clinical case studies exploring the abyss of madness. Pragmatic Case Studies in Psychotherapy [Online], Vol. 8(1), Article 1, 1-24. Available: http://hdl.rutgers.edu/1782.1/pcsp_journal

Aviv, R. (Dec. 2010). Which way madness lies: Can psychosis be prevented? Harper's Magazine, 35-46.

Carey, B. (2011, June 23). Expert on mental illness reveals her own fight. The New York Times, p. A1. 
Ellenberger, H.F. (1958). A Clinical introduction to psychiatric phenomenology and existential analysis. In R. May, E. Angel, \& H.H. Ellenberger (Eds.) Existence: A new dimension in psychiatry and psychology. New York: Basic Books.

Gross, G., Huber, G., Klosterkotter, J., et al. (2008). Bonn Scale for the Assessment of Basic Symptoms, $1^{\text {st }}$ Complete English Edition. Bonn, Germany: Shaker Verlag.

Jaspers, K. (1963). General psychopathology. Trans. J. Hoenig and M. Hamilton. Chicago: University of Chicago Press.

Karon, B.P. \& Vandenbos, G.R. (1977). Psychotherapy of schizophrenia: The treatment of choice. New York: Jason Aronson.

Laing, R.D. (1960). The divided self. New York: Penguin Books.

Levinas, E. (1969). Totality and infinity: An essay on exteriority. (A. Lingis, Trans.). Pittsburgh: Duquesne University Press.

Linehan, M.M. (1993). Cognitive-behavioral treatment of borderline personality disorder. New York: Guilford Press.

Lynch, D., Laws, K.R., \& McKenna, P.J. (2010). Cognitive behavioural therapy for major psychotic disorder: Does it really work? A meta-analytical review of well-controlled trials. Psychological Medicine, 40, 9-24.

Lysaker, P.H.,Johannesen, J.K. \& Lysaker, J.T. (2005). Schizophrenia and the experience of intersubjectivity as threat. Phenomenology and the Cognitive Sciences, 4, 335-352.

Moss, D. (2001). The roots and geneaology of humanistic psychology. In K.J. Schneider, J.F.T. Bugental, \& J.F. Pierson (Eds.) The handbook of humanistic psychology: Leading edges in theory, research and practice, pp. 5-20. Thousand Oaks, CA: Sage Publications.

Nelson, B. \& Sass, L.A. (2009). Medusa’s stare: A case study of working with self-disturbance in the early phase of schizophrenia. Clinical Case Studies, 8(6), 489-504.

Parnas, J. (2004). Belief and pathology of self-awareness: A Phenomenological contribution to the classification of delusions. Journal of Consciousness Studies, 11, 148-161.

Parnas, J., Moller, P., Kircher, T., et al. (2005). EASE: Examination of Anomalous SelfExperience. Psychopathology, 38, 236-258.

Parnas, J. \& Sass, L. (2001). Self, solipsism, and schizophrenic delusions. Philosophy, Psychiatry, Psychology, 8, 101-120.

Ratcliffe, M. (in preparation). Phenomenology as a form of empathy.

Saks, E.R. (2011). Psychoanalysis and the psychoses: Commentary on Kafka. Journal of the American Psychoanalytic Association, 59(1), 59-70.

Sass, L. A. (1992). Madness and Modernism. New York: Basic Books.

Sass, L.A. \& Parnas, J. (2003). Schizophrenia, consciousness, and the self. Schizophrenia Bulletin, 29(3), 427-444.

Sass, L.A. \& Pienkos, E. (in press). Delusion: The phenomenological approach. Oxford Handbook of Philosophy and Psychiatry. Oxford, UK: Oxford University Press.

Sass, L.A. \& Pienkos, E. (in preparation). Alienation and engulfment: A comparative phenomenology of melancholia, mania, and schizophrenia.

Stanghellini G., \& Ballerini, M. (2007). Values in persons with schizophrenia. Schizophrenia Bulletin, 33, 131-141.

Wykes, T. et al. (2008). Cognitive behavior therapy for schizophrenia: Effect sizes, clinical models, and methodological rigor. Schizophrenia Bulletin, 34(3), 523-537. 